\title{
Should heart age calculators be used alongside absolute cardiovascular disease risk assessment?
}

\author{
Carissa Bonner ${ }^{1,2^{*}}$ (D), Katy Bell ${ }^{1,3}$, Jesse Jansen ${ }^{1,2}$, Paul Glasziou ${ }^{1,3}$, Les Irwig ${ }^{1}$, Jenny Doust ${ }^{1,3}$ and Kirsten McCaffery ${ }^{1,2}$
}

\begin{abstract}
Background: National estimates of 'heart age' by government health organisations in the US, UK and China show most people have an older heart age than current age. While most heart age calculators are promoted as a communication tool for lifestyle change, they may also be used to justify medication when clinical guidelines advocate their use alongside absolute risk assessment. However, only those at high absolute risk of a heart attack or stroke are likely to benefit from medication, and it is not always clear how heart age relates to absolute risk. This article aims to: 1) explain how heart age calculation methods relate to absolute risk guidelines; 2) summarise research investigating whether heart age improves risk communication; and 3) discuss implications for the use of medication and shared decision making in clinical practice.

Main body: There is a large and growing number of heart age models and online calculators, but the clinical meaning of an older heart age result is highly variable. An older heart age result may indicate low, moderate or high absolute risk of a heart attack or stroke in the next 5-10 years, and the same individual may receive a younger or older heart age result depending on which calculator is used. Heart age may help doctors convey the need to change lifestyle, but it cannot help patients make an informed choice about medication to reduce CVD risk.

Conclusion: Interactive heart age tools may be helpful as a communication tool to initiate lifestyle change to reduce risk factors. However, absolute risk should be used instead of heart age to enable informed decision making about medication, to avoid unnecessary treatment of low risk people. Evidence-based decision aids that improve patient understanding of absolute risk should be considered as alternatives to heart age calculators for lifestyle and medication decisions.
\end{abstract}

Keywords: Cardiovascular risk, Risk assessment, Heart age, Overtreatment, Overdiagnosis

\section{Background}

A recent newspaper front page in the UK exclaimed "4 in 5 have a heart that is older than they are", with similar media reports in the US that " $40 \%$ of Americans had hearts that were five or more years older than their actual ages" [1,2]. These alarming statistics might suggest a need for mass medicalisation of the population with statins and blood pressure lowering drugs, but what does it really mean to have an older heart age? This article

\footnotetext{
* Correspondence: carissa.bonner@sydney.edu.au

${ }^{1}$ Wiser Healthcare Program, Sydney School of Public Health, The University of Sydney, Camperdown, NSW 2006, Australia

${ }^{2}$ Centre for Medical Psychology and Evidence-based Decision-making (CeMPED), The University of Sydney, Camperdown, NSW 2006, Australia Full list of author information is available at the end of the article
}

explores the idea that the heart age concept is highly variable and potentially misleading when it comes to deciding about whether or not to take preventive medication $[3,4]$. This is in contrast to guidelines advocating the use of heart age alongside absolute risk assessment for medication decision making [5]. The absolute risk of a heart attack or stroke is a better way to enable informed decision making and target treatment to those at highest risk who are most likely to benefit; while at the same time avoiding unnecessary labelling and treatment of low risk people [6, 7]. There is increasing awareness that we might be overdiagnosing and overtreating healthy, asymptomatic people, and that 'less is more' when the harms of an intervention outweigh the benefits [8]. Concerns about 'mass medicalisation' for 
cardiovascular disease (CVD) prevention have already been voiced following new guidelines in the UK and the US advocating much lower absolute risk thresholds for medication: halved from $20 \%$ to $10 \%$ over 10 years in the UK; and even lower to $7.5 \%$ in the US $[9,10]$.

This article aims to: 1) provide an overview of heart age calculation methods used in connection to absolute risk guidelines; 2) summarise research investigating whether heart age improves risk communication; and 3) discuss implications for the use of medication and shared decision making in clinical practice. We argue that the increasingly popular concept of heart age may contribute to mass medicalisation if used for the wrong purpose, and provide directions for future research to explore alternative risk communication formats that enhance informed decision making.

\section{Main text}

\section{What is heart age?}

Heart age generally involves an assessment of risk factors (e.g. age, sex, blood pressure, cholesterol, smoking and diabetes status) to estimate an individual's risk of CVD, which is then compared to a defined 'ideal' [11]. A heart age that is older than current age indicates elevated but modifiable risk, even if the absolute risk of a CVD event in the next 5-10 years is low [5, 11, 12] . For example, the New Zealand Heart Foundation (NZHF) assesses absolute risk in the next 5 years, and compares this to the age at which a person would reach the same absolute risk result if they did not smoke, had systolic blood pressure of $120 \mathrm{mmHg}$ and total/HDL cholesterol ratio of 4 [11]. Figure 1 shows how a 57 year old woman with elevated cholesterol would be assessed as having a low 5-year absolute risk of $4 \%$, but an older heart age of 64, since a woman with 'ideal' risk factor levels would not reach $4 \%$ risk for another 7 years (www.knowyournumbers.co.nz). This 'ideal' absolute risk approach is currently used to promote clinical practice guidelines in New Zealand and the UK $[5,11]$ but alternative methods compare a patient's risk factors to the average of the population [13, 14], or use the results of scans rather than absolute risk models [3].

\section{Where is heart age used?}

While New Zealand and the UK are the countries that most clearly link heart age to clinical medication guidelines $[5,11]$ millions of heart age assessments have been reported internationally in the academic literature. This includes a large study across 13 countries [15] and population estimates of heart age by government health organisations in the US (Centers for Disease Control and Prevention) [16], UK (National Health Service) [17] and China (National Center for Cardiovascular Disease) [18]. In the US, heart age calculators are being promoted by the federal government, local health organisations and industry, though guidelines do not yet appear to explicitly link them to medication recommendations. The Framingham study published a heart age assessment algorithm in 2008 [19], which was developed into an online tool on the Centers for Disease Control and Prevention $(C D C)$ website [20]. This calculator is promoted by the current Million Hearts campaign (federally run through the US Department of Health and Human Services, co-led by the $\mathrm{CDC}$ and the Centers for Medicare \& Medicaid Services) as a resource for doctors to use with their patients [21]. The CDC published a national estimate of 69.1 million "older" heart age assessments based on this algorithm in 2015 [16], highlighting socioeconomic and racial disparities which received some news coverage [2]. Heart age calculators are currently promoted by smaller organisations using various models and presentation formats, including university institutions, medical clinics and private companies [22-24]. More broadly, in 2009 Unilever partnered with the World Heart Federation to promote its heart age calculator and cholesterol-lowering food products internationally, leading to top Google rankings for "heart age" and at least 2.7 million users $[15,25]$. In Europe, vascular age for the SCORE model was published in 2010 [26], and a cardiovascular risk age calculator is recommended to communicate the need for lifestyle change to younger adults in 2016 cardiovascular prevention guidelines [27].

\section{How does heart age fit into CVD risk management?}

There are two distinct, and complementary, ways to manage CVD risk: lifestyle change to improve diet and physical activity, and medication to lower blood pressure and cholesterol. Motivating patients with CVD risk factors to change their lifestyle is important at any age, and this is where the heart age concept has been promoted as a potentially useful tool $[5,11,12]$. For example, a 25-year-old obese smoker needs to be motivated to give up smoking and improve their diet and exercise. Their chance of having a heart attack in the next few years will be low due to their young age, so telling them that their heart age is 35 may be a more compelling way to convey the need for lifestyle change. If they still have CVD risk factors at the age of 40 , a different approach is needed to make decisions about the benefits of commencing blood pressure and cholesterol-lowering medication. This requires an assessment of the absolute risk of a CVD event (e.g. heart attack or stroke) in the next 5 to 10 years, in order to estimate the benefit an individual patient is likely to gain from taking medication [28].

Problems may arise if heart age is used to inform medication decisions rather than motivate lifestyle 

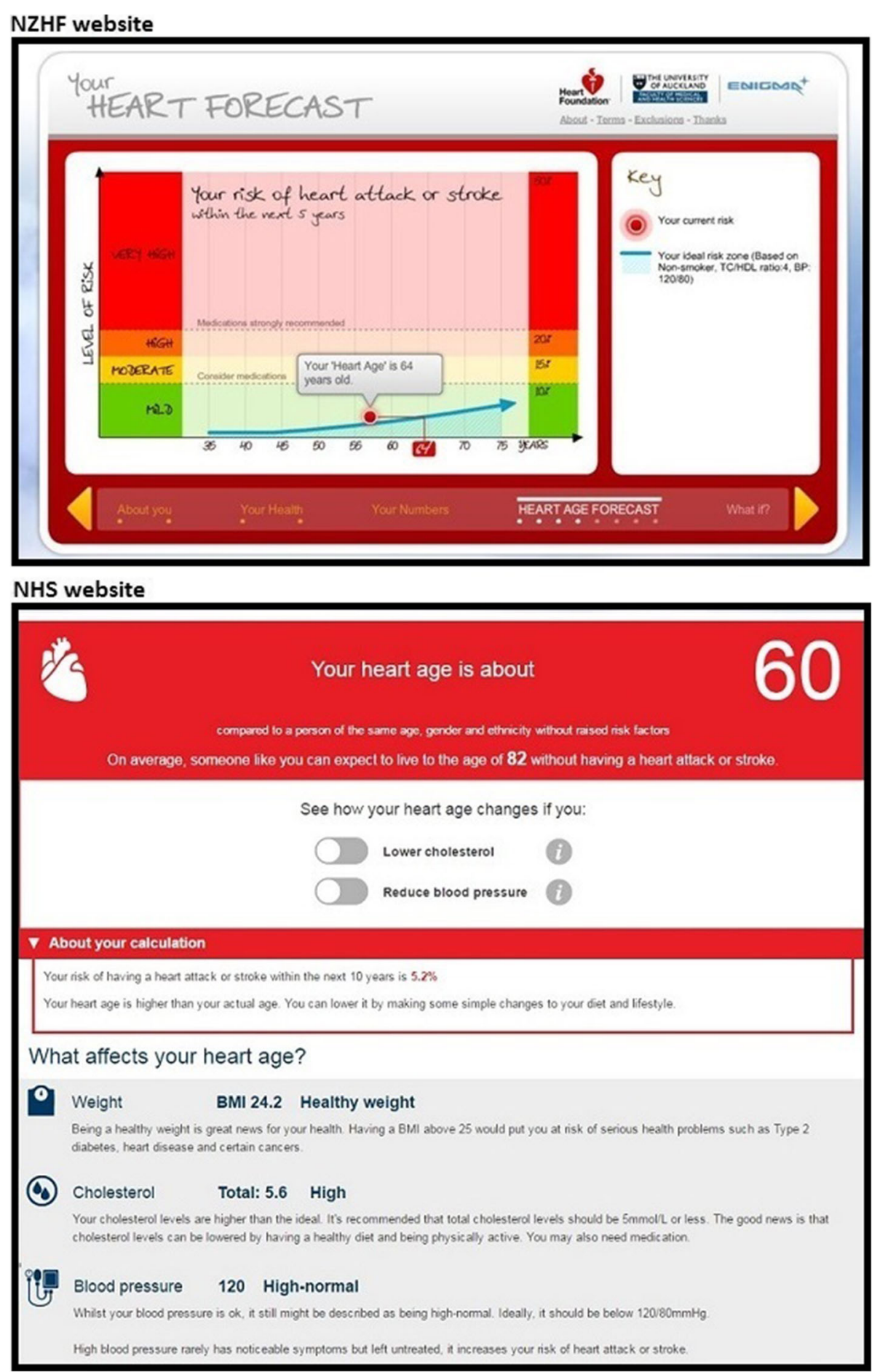

Fig. 1 Two heart age calculator results for low absolute risk but older heart age (for Case 1 in Table 1: 57 year old woman with elevated cholesterol and no other risk factors; www.knowyournumbers.co.nz; www.nhs.uk/tools/pages/heartage.aspx) (2017 version)

change. This is increasingly likely as more heart age assessment methods are developed and implemented alongside medication guidelines based on absolute risk $[3,5,11]$. There are now multiple heart age calculators linked to clinical practice guidelines and available to the public, conveying conflicting messages about risk and medication. It is essential that doctors and patients understand the assumptions behind these heart age calculators and how they relate to absolute risk-based medication guidelines. 
Does heart age improve risk communication?

It can be challenging to communicate CVD risk to patients $[12,29]$. Heart age has been promoted as a potentially useful way to explain lifetime CVD risk, particularly for younger people who need to change their lifestyle but are at low risk of a CVD event in the next few years [5, 11]. Clinical trials have shown that paper-based and online risk assessments that include heart age can be beneficial and improve risk factor management compared to standard care with verbal counselling about absolute risk [13, $14,30]$. However, these trials have not directly compared heart age to absolute risk in the same visual format, so although we can say that communicating heart age alongside other CVD risk information can have an effect, we can't say whether that is due to using heart age instead of absolute risk. Direct experimental comparisons in the general population have found a recall benefit and more emotional impact (e.g. increased worry) of heart age compared to absolute risk, but no advantage for motivating lifestyle change [4, 31, 32]. One of these studies found increased patient misunderstandings about risk level and concerns about credibility in the heart age group [4]. This suggests a need for doctors to explain heart age within the consultation to ensure patients adequately understand their risk and its implications.

Overall, the research suggests that heart age is a more emotionally engaging format for communicating CVD risk to patients, and visual heart age formats may improve risk factor management compared to standard care involving verbal explanations of absolute risk. However, discussions about medication need to be based on absolute risk rather than heart age, because the likelihood of benefit depends on the likelihood of risk. To make an informed decision about medication, patients need to understand their baseline absolute risk, because the probability of preventing CVD with treatment is directly proportional to this [33, 34]. For example, 100 asymptomatic people with a 10 -year absolute risk of $10 \%$ would need to take statins for 10 years in order to prevent 2 CVD events; the other 98 people would not benefit ( 90 would not have an event and 8 would have an event despite treatment). Not everyone will think it is worth the cost, inconvenience and side effects to reduce their individual risk from $10 \%$ to $8 \%$ (see Fig. 2). In this context a shared decision making approach is particularly important, which requires clear communication about the absolute risk of a CVD event, and the absolute benefit of medication [6, 10, 35]. Heart age may help doctors to convey the need for lifestyle change at any level of absolute risk, but it cannot help patients make an informed choice about medication. Further research is needed to investigate the effect of different risk calculation and presentation methods: single versus multiple risk formats (such as combining the percentage with verbal risk level and graphs showing frequency), comparison to average versus ideal risk factors, and use of absolute risk versus scan-based methods of heart age calculation [3].

\section{Why do heart age calculators give different recommendations for the same patient?}

The relationship between heart age and absolute risk thresholds for medication can be very variable $[5,11]$. Figure 1 demonstrates two different approaches. The NZHF calculator (www.knowyournumbers.co.nz) explains the relationship between absolute risk and heart age, with medication thresholds based on 5-year absolute risk in line with clinical guidelines. Maintaining 'ideal' risk factor levels means that you stay below the medication threshold even with increasing age. The Joint British Societies (JBS) and National Health Service (NHS) heart age calculators (www.jbs3risk.com/pages/risk_calculator.htm; www.nhs.uk/tools/pages/heartage.aspx) estimate 10-year absolute risk, with a separate calculation for heart age based on an annual rate derived from the QRISK lifetime model [4]. The approach to medication is quite different:

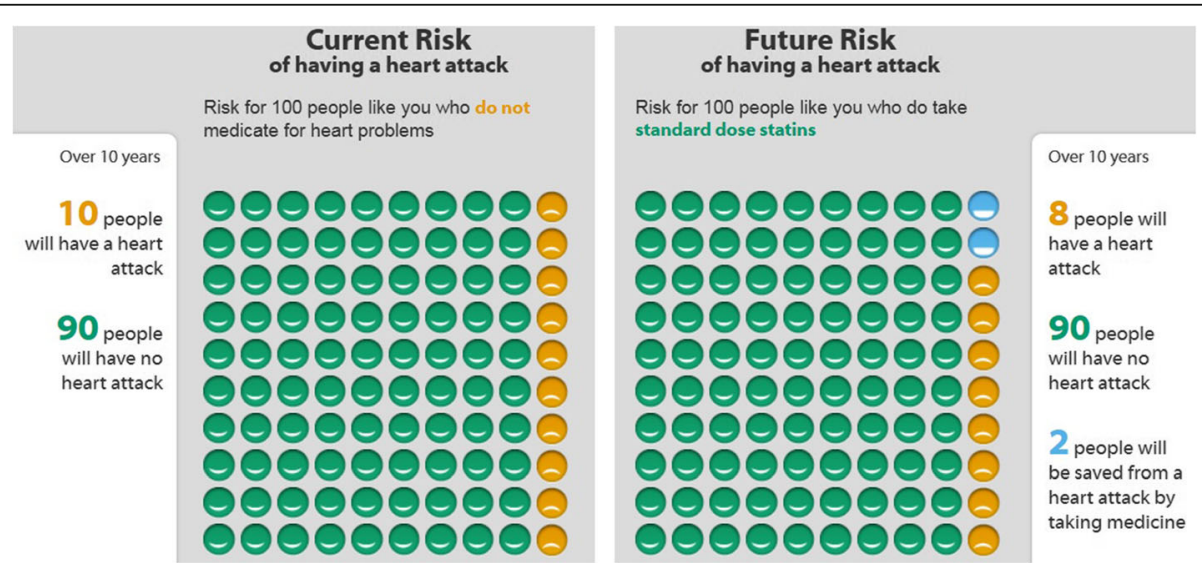

Fig. 2 Example of an absolute CVD risk tool from the Mayo Clinic Statin Choice decision aid. (for 10\% risk of a CVD event over the next 10 years; https://statindecisionaid.mayoclinic.org/) (2017 version) 
users are informed that they may need medication based on older heart age, even if their 10-year absolute risk is low. The message conveyed here is that medication is an option regardless of the absolute risk and benefit, which is contrary to the absolute risk approach used in CVD prevention guidelines.

To demonstrate this, we entered real patients' risk factor values from a previous study of the NZHF calculator into the 2017 version of the NHS calculator [36]. The examples in Table 1 show how people with isolated risk factors but low absolute risk would receive different heart age results and medication information depending on whether they use the NZHF or NHS calculator. For example, Case 1 is a 57 year old non-smoking woman with elevated cholesterol but 'ideal' blood pressure, body mass index (BMI) in the healthy range, and no other risk factors. She would receive an older heart age estimate on both the NZHF (64) and NHS (60) websites, but a low absolute risk result of $4 \%$ over 5 years or $5 \%$ over 10 years. Both the heart age and absolute risk numbers vary due to different underlying models, but the key issue to note for this paper is how "older heart age" is related to medication recommendations. NZHF describes the risk category as mild and below the medication threshold based on absolute risk, while the NHS calculator suggests that both cholesterol and blood pressure medication may be needed, even though the absolute risk is low in both cases. In contrast, if we entered the same risk factors into the American College of Cardiology/American Heart Association (ACC/AHA) absolute risk calculator within the Statin Choice decision aid (see Fig. 2) [37], we would find that 100 people need to take cholesterol medication for 10 years to prevent 1 heart attack, 3 would have a heart attack anyway, and the remaining 96 would never have had a heart attack in the first place. Heart age cannot convey this information.

As well as using different CVD risk models, risk factor thresholds may differ between calculators. Heart age is based on comparison to an 'ideal', which requires the use of multiple thresholds for individual risk factors. For example, Case 1 is right on the threshold for blood pressure $(120 \mathrm{mmHg})$ so she is given the message that her CVD risk is higher than normal on the NHS website; whereas this is described as 'ideal' on the NZHF website (2017 versions). The NHS website also says that cholesterol medication may be needed despite being well under the absolute risk medication threshold of $10 \%$. The heart age results in Table 1 are not widely different in absolute terms, but there is a psychological difference between having a younger and older heart age [36].

The examples above show how different heart age calculators can lead to different medication recommendations. This suggests that patients with the same risk factors may perceive their risk differently and receive different treatment recommendations depending on which calculator their doctor uses; potentially leading to unwarranted practice variation. These differences will become even greater when using average rather than ideal risk factors [13, 14], or scanbased methods of calculation rather than absolute risk [3].

How does heart age relate to medication decision making? Using heart age to recommend medication is likely to undermine the absolute risk approach for medication

Table 1 Examples of different heart age results for the same patient using different calculators

\begin{tabular}{|c|c|c|c|}
\hline Patient profile & Risk factors & NZ: HF website & UK: NHS website \\
\hline $\begin{array}{l}\text { Case } 1 \text { with elevated cholesterol but 'ideal' blood pressure } \\
\text { would receive an older heart age estimate on both } \\
\text { calculators, with two medications suggested for the } \\
\text { lower result }\end{array}$ & $\begin{array}{l}\text { Age: } 57 \\
\text { Sex: female } \\
\text { Systolic BP: } 120 \\
\text { Chol ratio: } 5.6 \\
\text { BMI: } 24 \\
\text { Smoking: no } \\
\text { Diabetes: no }\end{array}$ & $\begin{array}{l}\text { Older heart age }(64) \\
5 \mathrm{yr} \text {. absolute risk }=4 \% \\
\text { Mild risk below } \\
\text { medication threshold }\end{array}$ & $\begin{array}{l}\text { Older heart age }(60) \\
10 \text { yr. absolute risk }=5 \% \\
\text { May need chol \& blood } \\
\text { pressure medication }\end{array}$ \\
\hline $\begin{array}{l}\text { Case } 2 \text { with elevated blood pressure but lower than } \\
\text { 'ideal' cholesterol would receive an older heart age } \\
\text { on NZHF or the same heart age as current age on } \\
\text { NHS, with one medication suggested for the lower } \\
\text { result }\end{array}$ & $\begin{array}{l}\text { Age: } 62 \\
\text { Sex: male } \\
\text { Systolic BP: } 130 \\
\text { Chol ratio: } 3.5 \\
\text { BMI: } 25 \\
\text { Smoking: no } \\
\text { Diabetes: no }\end{array}$ & $\begin{array}{l}\text { Older heart age }(63) \\
5 \mathrm{yr} \text {. absolute risk }=7 \% \\
\text { Mild risk below } \\
\text { medication threshold }\end{array}$ & $\begin{array}{l}\text { Same heart age }(62) \\
10 \text { yr. absolute risk }=9 \% \\
\text { May need blood } \\
\text { pressure medication }\end{array}$ \\
\hline $\begin{array}{l}\text { Case } 3 \text { with obesity but 'ideal' blood pressure and } \\
\text { cholesterol would receive a younger heart age on } \\
\text { NZHF or an older heart age on NHS, with one } \\
\text { medication suggested for the higher result }\end{array}$ & $\begin{array}{l}\text { Age: } 48 \\
\text { Sex: female } \\
\text { Systolic BP: } 120 \\
\text { Chol ratio: } 4 \\
\text { BMI: } 38 \\
\text { Smoking: no } \\
\text { Diabetes: no }\end{array}$ & $\begin{array}{l}\text { Young heart age }(<48) \\
5 \mathrm{yr} \text {. absolute risk }=1 \% \\
\text { Mild risk below } \\
\text { medication threshold }\end{array}$ & $\begin{array}{l}\text { Older heart age (49) } \\
10 \mathrm{yr} \text {. absolute risk }=2 \% \\
\text { May need blood } \\
\text { pressure medication }\end{array}$ \\
\hline
\end{tabular}

Chol ratio total/HDL cholesterol ratio, BMI body mass index, NZ HF New Zealand Heart Foundation website (www.knowyournumbers.co.nz) (2017 version), UK NHS United Kingdom National Health Service website (www.nhs.uk/tools/pages/heartage.aspx) (2017 version) 
decisions. The use of absolute risk to make treatment decisions, instead of treating blood pressure and cholesterol as isolated risk factors, allows medication to be targeted to those at highest risk who are most likely to benefit by prevention of a CVD event within 5-10 years. This approach aims to prevent both over-treatment of low risk and under-treatment of high risk individuals [28].

However, while JBS3 guidelines focus on absolute risk assessment, they also recommend that medication should be considered for people with low absolute risk but older heart age than current age [5]. This is likely to further lower the threshold for medication, and lead to over-treatment of low risk individuals. National estimates of heart age by government health organisations in the US, UK and China show how this approach could lead to 'mass medicalisation', as the majority of the general population has an older heart age than current age. The CDC found that every age strata had an older heart age than current age on average, and 69.1 million (43.7\%) people aged $30-74$ had a heart age $>5$ years older than current age [16]. The first 1.4 million users of the UK National Health Service heart age tool indicated that $79 \%$ had an older heart age than current age in every age strata, including 69\% of users under 40 years, who are at low absolute risk of CVD [17]. The China National Centre for Cardiovascular Disease analysed heart age assessments for 18,214 people and found a mean heart age 10 years older than current age, despite a low 10-year CVD risk of 4\% [18]. Similarly, an international study of 2.7 million people (31\% UK) found an average heart age 4 years older than current age [15].

Other risk format suggestions in the cardiovascular literature include relative risk, lifetime risk and percentiles [12], but they all have the same problem as heart age: they do not enable patients to make an informed choice about medication benefits and harms based on current research evidence. The 2016 European guidelines make a clearer distinction between absolute risk for medication and heart age for lifestyle, stating directly: "both risk age and lifetime risk are closer to relative than absolute risk, and none provides an evidence base for drug treatment decisions" [27]. Table 2 demonstrates how to avoid the potential harms of using heart age to justify medication.

\section{What could we use instead of heart age?}

The risk communication and decision aid literature provides clear directions for alternative absolute risk formats that could be used to explain CVD risk and the benefits of both lifestyle and medication interventions. This should be based on outcomes that are meaningful to patients, focusing on the likelihood of experiencing a CVD event rather than how far blood pressure or cholesterol deviates from an arbitrary 'ideal' threshold
$[6,10,35]$. We know that the absolute risk of a CVD event is easier to understand than relative risk, and that multiple formats will cover different patient information preferences and learning styles [38]. This should include verbal explanation of the frequency of CVD events for a given absolute risk result, and visual formats showing the risks and benefits of all lifestyle and medication options in absolute terms [38]. Recent qualitative research investigating such visual formats demonstrated how patients find absolute risk more meaningful when both lifestyle and medication intervention effects can be explored in relation to this (e.g. using the risk calculator at http://chd.bestsciencemedicine.com/calc2.html) (2017 version) [39]. There is strong evidence from a Cochrane systematic review of 105 randomised controlled trials that providing this sort of information in the form of a patient decision aid improves patient knowledge, accuracy of risk perception, doctor-patient communication, and decision making that is consistent with individual values and preferences [40]. For example, the Statin Choice decision aid is an evidence-based, effective tool that demonstrates how this can be done (Fig. 2), but it could be improved by allowing lifestyle interventions to be compared to medication options [37].

In the context of CVD prevention, where the majority of asymptomatic people may be told they are high risk based on heart age assessment, but the likelihood of benefiting from medication depends on absolute risk, clear communication to enable shared decision making is especially important [41]. This requires populationbased absolute risk and treatment efficacy data to be provided to the patient in a transparent way.

"When we offer statins, or any preventive treatment, we are practicing a new kind of medicine, very different to the doctor treating a head injury in A\&E. We are less like doctors, and more like a life insurance

Table 2 Why caution should be used when linking heart age to medication

\footnotetext{
- Practice variation: Heart age results may be younger, the same or older than current age for the same risk factors, depending on the CVD risk model and ideal risk factor thresholds used to calculate heart age; so it is important for doctors to understand the assumptions behind these calculators in order to avoid unwarranted practice variation.

- Uninformed decision making: Patients cannot understand the chance of benefiting from preventive CVD medications such as statins and blood pressure lowering drugs without knowing the baseline absolute risk; so the relationship between heart age, absolute risk and recommended medication thresholds needs to be explained to enable informed decision making.

- Over-treatment: Using heart age to decide on the need for drugs will lead to treatment of people who are very unlikely to experience a CVD event in the next 5-10 years; so treatment decisions should be made on the basis of absolute risk and not heart age.
} 
sales team: offering occasional benefits, many years from now, in exchange for small ongoing costs. Patients differ in what they want to pay now, in side effects or inconvenience, and how much they care about abstract future benefits. Crucially, the benefits and disadvantages are so closely balanced that these individual differences really matter." (Ben Goldacre, BMJ 2014) [10].

\section{Conclusions}

The heart age concept has intuitive appeal, but it can also be used to justify treatment of low risk people who are very unlikely to benefit in the short term from taking medication. The assumptions behind heart age calculators need to be made clear and explicit so that both doctors and patients can understand why they may get different results on different calculators. They also need to understand that this is a relative measure, where an individual is compared to a specific definition of the 'ideal'. Informed medication decisions should be based on absolute risk and benefit rather than heart age, and evidence-based communication formats such as decision aids should be used to avoid uninformed decision making and overtreatment of healthy, asymptomatic people who are at low risk of a heart attack or stroke.

\section{Abbreviations}

A\&E: Accident \& Emergency Department; ACC/AHA: American College of Cardiology/American Heart Association; BMI: Body mass index; BMJ: British Medical Journal; CDC: Centers for Disease Control and Prevention; CVD: Cardiovascular disease; HDL: High-density lipoprotein; JBS: Joint British Societies; NHS: National Health Service; NZHF: New Zealand Heart Foundation; UK: United Kingdom; US: United States of America

\section{Acknowledgements}

We thank Lyndal Trevena for helpful comments on an earlier version of this paper.

\section{Funding}

This work has been supported through the National Health and Medical Research Council of Australia via the Screening and Test Evaluation Program (STEP) and Wiser Healthcare Program. The funder had no role in study design, data collection, analysis, interpretation of data, or writing.

\section{Availability of data and materials}

N/A

\section{Authors' contributions}

$\mathrm{CB}$ drafted the manuscript based on her PhD work including two heart age studies: made substantial contributions to conception, analysis and interpretation; critically revised the draft; approved the final version; and agrees to be accountable for all aspects of the work. KB made substantial contributions to analysis and interpretation; critically revised the draft; approved the final version; and agrees to be accountable for all aspects of the work. JJ made substantial contributions to analysis and interpretation; critically revised the draft; approved the final version; and agrees to be accountable for all aspects of the work. PG made substantial contributions to conception and interpretation; critically revised the draft; approved the final version; and agrees to be accountable for all aspects of the work. LI made substantial contributions to conception and interpretation; critically revised the draft; approved the final version; and agrees to be accountable for all aspects of the work. JD made substantial contributions to conception and interpretation; critically revised the draft; approved the final version; and agrees to be accountable for all aspects of the work. KM made substantial contributions to conception and interpretation; critically revised the draft; approved the final version; and agrees to be accountable for all aspects of the work.

\section{Authors' information}

This ideas presented in this article were developed and discussed over several years based on absolute CVD risk and overdiagnosis research within the STEP and Wiser Healthcare Programs. The release of new guidelines in the US and UK, including the JBS3 suggestion that medication could be prescribed based on heart age, prompted this paper to be written. CB is a behavioural scientist who wrote the paper based on her $\mathrm{PhD}$ research investigating CVD risk communication and decision making, including two heart age studies. KB and LI are clinical epidemiologists with expertise in test evaluation and CVD risk models. JJ and KM are psychologists with expertise in shared decision making and risk communication. PG and JD are academic GPs with expertise in evidence-based practice and clinical CVD guidelines.

\section{Ethics approval and consent to participate \\ $\mathrm{N} / \mathrm{A}$}

\section{Consent for publication}

N/A

\section{Competing interests}

The authors declare they have no competing interests.

\section{Publisher's Note}

Springer Nature remains neutral with regard to jurisdictional claims in published maps and institutional affiliations.

\section{Author details}

${ }^{1}$ Wiser Healthcare Program, Sydney School of Public Health, The University of Sydney, Camperdown, NSW 2006, Australia. ${ }^{2}$ Centre for Medical Psychology and Evidence-based Decision-making (CeMPED), The University of Sydney, Camperdown, NSW 2006, Australia. ${ }^{3}$ Faculty of Health Sciences and Medicine, Bond University, Robina, QLD 4229, Australia.

Received: 2 October 2017 Accepted: 26 January 2018

Published online: 07 February 2018

\section{References}

1. Borland S. Four in five Britons have a heart that is older than they are: obesity and lack of exercise to blame for premature ageing. Daily Mail. 2016;29 http://www.dailymail.co.uk/health/article-3812741/Four-five-Britonsheart-older-Obesity-lack-exercise-blame-premature-ageing.html. Accessed 15 Aug 2017.

2. Kounang N. Here's how to calculate your heart's age. CNN. 2015;29 http:// edition.cnn.com/2015/09/01/health/heart-age-calculator/index.html. Accessed 15 Aug 2017.

3. Groenewegen KA, den Ruijter HM, Pasterkamp G, Polak JF, Bots ML, Peters SAE. Vascular age to determine cardiovascular disease risk: a systematic review of its concepts, definitions, and clinical applications. Eur J Prev Cardiol. 2016;23(3):264-74.

4. Bonner C, Jansen J, Newell BR, et al. Is the 'heart age' concept helpful or harmful compared to absolute cardiovascular disease risk? An experimental study. Med Decis Mak. 2015:35(8):967-78.

5. Joint British Societies. Joint British Societies' consensus recommendations for the prevention of cardiovascular disease (JBS3). Heart. 2014;100:ii1-ii67.

6. Montori VM, Brito JP, Ting HH. Patient-centered and practical application of new high cholesterol guidelines to prevent cardiovascular disease. JAMA. 2014;311(5):465-6.

7. Moynihan R, Doust J, Henry D. Preventing overdiagnosis: how to stop harming the healthy. BMJ. 2012;344:e3502.

8. Moynihan R, Heneghan C, Godlee F. Too much medicine: from evidence to action. BMJ. 2013:347:f7141.

9. $\quad$ Editorial. Statins for millions more? Lancet. 2014;383(9918):669.

10. Goldacre BM. Statins are a mess: we need better data, and shared decision making. BMJ. 2014;348:g3306. 
11. Wells S, Kerr A, Eadie S, Wiltshire C, Jackson R. 'Your heart Forecast': a new approach for describing and communicating cardiovascular risk? Heart. 2010;96(9):708-13.

12. Cuende JI. Vascular age versus cardiovascular risk: clarifying concepts. Rev Esp Cardiol. 2016;69:243-6.

13. Grover $S A$, Lowensteyn I, Joseph $L$, et al. Patient knowledge of coronary risk profile improves the effectiveness of dyslipidemia therapy: the CHECK-UP study: a randomized controlled trial. Arch Intern Med. 2007;167(21):2296-303.

14. Lowensteyn I, Joseph L, Levinton C, Abrahamowicz M, Steinert Y, Grover SA. Can computerized risk profiles help patients improve their coronary risk? The results of the coronary health assessment study (CHAS). Prev Med. 1998;27(5, pt1):730-7.

15. Neufingerl N, Cobain MR, Newson RS. Web-based self-assessment health tools: who are the users and what is the impact of missing input information? J Med Internet Res. 2014;16(9):e215.

16. Yang Q, Zhong Y, Ritchey M. Cobain, et al. vital signs: predicted heart age and racial disparities in heart age among U.S. adults at the state level. MMWR Morb Mortal Wkly Rep. 2015;64(34):950-8.

17. Patel RS, Lagord C, Waterall J, Moth M, Knapton M, Deanfield JE. Online self-assessment of cardiovascular risk using the joint British societies (JBS3)-derived heart age tool: a descriptive study. BMJ Open. 2016;6(9):e011511.

18. Shi R, Lan Y, Lu C, Yu W. Abstract 051: a feasibility study on 10-year CVD risk assessment as a primary prevention tool for cardiovascular disease. Circ Cardiovasc Qual Outcomes. 2017;10(Suppl 3):A051.

19. D'Agostino RB, Vasan RS, Pencina MJ, Wolf PA, Cobain M, Massaro JM, Kannel WB. General cardiovascular risk profile for use in primary care. Circulation. 2008;117(6):743-53.

20. Centers for Disease Control and Prevention. Heart age predictor using BMI. https://www.cdc.gov/vitalsigns/cardiovasculardisease/heartage.html. Accessed 15 Aug 2017. 2015.

21. Million Hearts. Tools. https://millionhearts.hhs.gov/tools-protocols/tools.html. Accessed 15 Aug 2017

22. Club Red University of Virginia, Heart and Vascular Centre. Heart Age Calculator. http://clubreduva.com/heart_101/heart-age-calculator/. Accessed 15 Aug 2017

23. The Guthrie Clinic. Know Your Heart Age. https://www.guthrie.org/knowyour-heart-age. Accessed 15 Aug 2017.

24. Everist Genomics Everist Health. Vascular Age Calculator. http://www. everisthealth.com/tools/calculator/. Accessed 15 Aug 2017.

25. Case study: Unilever heart age tool. Gorkana. 2010;5. http://pr.gorkana.co.uk/ news/all/case-studies/case-study-unilever-heart-age-tool-2/. Accessed 15 Aug 2017.

26. Cuende Jl, Cuende N, Calaveras-Lagartos J. How to calculate vascular age with the SCORE project scales: a new method of cardiovascular risk evaluation. Eur Heart J. 2010;31:2351-8.

27. Piepoli MF, Hoes AW, Agewall S, et al. 2016 European guidelines on cardiovascular disease prevention in clinical practice: the sixth joint task force of the European Society of Cardiology and Other Societies on cardiovascular disease prevention in clinical practice (constituted by representatives of 10 societies and by invited experts). Eur Heart J. 2016:37:2315-81.

28. Jackson R, Lawes CMM, Bennett DA, Milne RJ, Rodgers AR. Treatment with drugs to lower blood pressure and blood cholesterol based on an individual's absolute cardiovascular risk. Lancet. 2005;365(9457):434-41.

29. Jackson R, Kerr A, Wells S. 'Should we reconsider the role of age in treatment allocation for primary prevention of cardiovascular disease?' No, but we can improve risk communication metrics. Eur Heart J. 2017; 38(20):1548-52.

30. Lopez-Gonzalez AA, Aguilo A, Frontera M, et al. Effectiveness of the heart age tool for improving modifiable cardiovascular risk factors in a southern European population: a randomized trial. Eur J Prev Cardiol. 2015;22(3):389-96.

31. Soureti A, Hurling R, Murray P, van Mechelen W, Cobain M. Evaluation of a cardiovascular disease risk assessment tool for the promotion of healthier lifestyles. Eur J Cardiovasc Prev Rehabil. 2010;17(5):519-23.

32. Witteman $\mathrm{HO}$, Fuhrel-Forbis A, Wijeysundera HC, et al. Animated randomness, avatars, movement, and personalization in risk graphics. J Med Internet Res. 2014;16(3):294-313. (Multimedia Appendix 3)

33. Cholesterol Treatment Trialists Collaborators. The effects of lowering LDL cholesterol with statin therapy in people at low risk of vascular disease: meta-analysis of individual data from 27 randomised trials. Lancet. 2012; 380(9841):581-90.
34. The Blood Pressure Lowering Treatment Trialists' Collaboration. Blood pressure-lowering treatment based on cardiovascular risk: a meta-analysis of individual patient data. Lancet. 2014;384(9943):591-8.

35. Otto CM. Statins for primary prevention of cardiovascular disease. BMJ. 2016; 355: 6334

36. Bonner C, Jansen J, Newell BR, et al. I don't believe it, but l'd better do something about it: patient experiences of online heart age risk calculators. J Med Internet Res. 2014;16(5):e120.

37. Mann DM, Ponieman D, Montori VM, Arciniega J, McGinn T. The Statin choice decision aid in primary care: a randomized trial. Patient Educ Couns. 2010:80(1):138-40.

38. Trevena $L$, Zikmund-Fisher BJ, Edwards $E$, et al. Presenting quantitative information about decision outcomes: a risk communication primer for patient decision aid developers. BMC Med Inform Decis Mak. 2013;13(S2):S7.

39. Bonner C, McKinn S, Lau A, Jansen J, Doust J, Trevena L, McCaffery K. Heuristics and biases in cardiovascular disease prevention: How can we improve communication about risk, benefits and harms? Patient Education \& Counseling. In press, available online 11 Dec 2017: https://doi.org/10. 1016/j.pec.2017.12.003.

40. Stacey D, Legare F, Lewis $K$, et al. Decision aids for people facing health treatment or screening decisions. Cochrane Database Syst Rev. 2017;4: CD001431.

41. Redberg RF, Katz MH. Statins for primary prevention: the debate is intense, but the data are weak. JAMA Intern Med. 2016:316(19):1979-81.

\section{Submit your next manuscript to BioMed Central and we will help you at every step:}

- We accept pre-submission inquiries

- Our selector tool helps you to find the most relevant journal

- We provide round the clock customer support

- Convenient online submission

- Thorough peer review

- Inclusion in PubMed and all major indexing services

- Maximum visibility for your research

Submit your manuscript at www.biomedcentral.com/submit
) Biomed Central 